\section{Calculating Chilling Hours}

I am writing out of frustration trying to program the equations and find the background information cited in the Feature article by Linvill [HortScience 25(1):14-16, Jan. 1990].

The subject matter of this article is indeed deserving of the Feature position in HortScience. The author's claim that this method can be invoked using daily min-max temperatures carries important operation application. Chilling hours is an important subject for container- and field-grown conifer crops in British Columbia. However, since Feature articles are solicited by the Science Editor, I would have expected that the editing and review would be fairly tight. Some of the shortcomings of the article may rest with the author; however, the formalting and presentation problems are the editor's responsibility.

My specific questions are:

1) Calculation of daylength using the equations cited in the article do not give correct daylengths. Manifestations of this mis calculation ripple through all derived calculations.

2) Substituting actual climate data with freezing minimum temperatures does not yield meaningful nighttime chilling hours. Perhaps ${ }^{\circ} \mathrm{F}$ rather than ${ }^{\circ} \mathrm{C}$ are to be used?

3) Order of precedence in equations could be made less ambiguous.

4) Table giving algorithm for conversion of temperature to chilling units is ambiguous and should have been formatted differently.

5) Where are the cited Richardson articles (Richardson, 1974; 1984)?

6) Algorithm for Eq. [3] is ambiguous.

7) Repeat(?)/missing(?) information at the bottom of p. 14/top of p. 15?

Since the author apparently used validatory data from Clemson, S.C., it would be useful to provide a portion of this data to allow readers, such as myself, to proof the equations for ourselves.

Robert K. Scagel Pacific Phytometric Consultants 1531-133B Street

Surrey, B.C. V4A 6A5, Canada

I am interested in developing a simulation of the diurnal temperature cycle based on daily minimum and maximum temperatures, and so was pleased to see this article in the January issue of HortScience. Unfortunately, there are several (typographical?) errors in the equations that gave me some consternation until I figured them out. Hopefully, this text will help others who are interested in the models given in that paper.

1) Eq. [2] is listed in the paper as:

$$
\mathrm{T}(\mathrm{t})=\mathrm{Ts}-\left[\left(\mathrm{Ts}-\mathrm{T}_{\min }\right) / \ln (24-\mathrm{DL})\right] \mathrm{x}
$$

HortScience, Vol. 26(2), February 1991
This should be corrected to the following:

$$
\begin{gathered}
\mathrm{T}(\mathrm{t})=\mathrm{Ts}-\left[\left(\mathrm{Ts}_{\mathrm{s}}-\mathrm{T}_{\min }\right) /[(\ln (24)-\mathrm{DL})] \mathrm{x}\right. \\
\{\ln (\mathrm{t})-\ln (\mathrm{DL})],
\end{gathered}
$$

where $t$ is solar time (unclear in the article). This equation is valid for times greater than DL. (Not " $T(t)$ is temperature at time $t>1$ $\mathrm{hr}$ after sunset...", it is usable $1 \mathrm{~ms}$ after sunset.

2) The equations for DL (daylength) given between Eqs. [3] and [4] need further explanation. Latitude (LAL) is given in degrees, and must be converted to radians for proper computation with most calculators/ computers. The expression: $\cos (0.172 \times$ $C D-1.95)$ is correct if all values are considered to be in radians.

3) The equation for daylength (DL) if latitude is $>40$ should be changed from:

$$
\begin{gathered}
\mathrm{DL}=12.25+[(1.6264+1.7643 \mathrm{X} \\
\tan (\mathrm{LA})]^{2} \times \cos (0.0172 \times \mathrm{CD}-19.5)
\end{gathered}
$$

to

$$
\begin{gathered}
\mathrm{DL}=12.25+\{1.6264+1.7643 \mathrm{X} \\
\left.[\tan (\mathrm{LA})]^{2} \times \cos (0.0172 \times \mathrm{CD}-19.5)\right\}
\end{gathered}
$$

I have not checked the accuracy of Eqs. [4] and [5], only Eqs. [1] through [3].

Finally, I hope that these corrections are of use to anyone considering using this model.

\section{Steve Wiest Dept. of Horticulture Kansas State Univ. Manhattan, KS 66506}

\section{Author's response}

The following comments clarify questions asked by Scagel and Wiest.

Wiest (1): Comments on nighttime cooling equation.

There are several papers now in the literature comparing mathematical equations that describe Earth's daily heating cycle. These equations range through exponential, sinusoidal, straight line, logarithmic, and now log-log nighttime cooling simulations. Some have one-section, some have two-section cooling curves. Some have the capability to determine local constants that "improve" the curve fit to real data. I realize that no equation can duplicate natural cooldown every time. There are too many parameters not modeled (i.e., wind, clouds, soil moisture) that influence heat loss from Earth's surface.

I wanted a curve representative of available data and that went along with Brunt's theory presented by Sutton (1953), which suggested that nighttime cooling is a function of the square root of cooling time. The curve presented in Eq. [2] was an improve- ment over others published in the late 1970s, when this work was initiated (Parton and Logan, 1981).

Wiest suggest the following replacement for nighttime cooling (Eq. [2]):

$$
\begin{gathered}
T(t)=T s-\left[\left(T s-T_{\min }\right) /[(\ln (24)-D L)] x\right. \\
\{\ln (t)-\ln (D L)] .
\end{gathered}
$$

Performing a unit analysis of this equation reveals mixed units, temperature per unit time, in the second part of the righthand side. The right-hand side must have units of temperature. The logarithmic expression must be dimensionless, as I show in my cooling curve (Eq. [2]):

$$
T(t)=T s-\left[\left(T s-T_{\min }\right) / \ln (24-D L] \times \ln (t) .\right.
$$

A comment was made on the use of time in these equations and the relationship to solar time. When using the solutions pre sented for chill hours or chill units, it is not necessary to determine the exact time of day. All times can be determined relative to sunrise for the day calculation and to sunset for the nighttime curve. This makes programming a whole lot easier since we do not have to keep track of exact local time or convert to Coordinated Universal Time.

There is one major problem with the presentation of the cooling equation and the use of "time". I should have stated that, in Eq. [2], 1 is equivalent to sunset time rather than indicating time $>1 \mathrm{hr}$ after sunset. The natural $\log$ of 1 is 0 , which results in temperature at 1 equal to sunset temperature, $\mathrm{T}(1)=$ $\mathrm{T}_{\text {sunse }}$

Wiest (2) and (3); Scagel (6): Calculation of climatological day and daylength.

The climatological day algorithm is in the cited paper by Stuff (1973). The other equations are not in that paper, much to my chagrin. I have been using these equations for so long that I naturally placed them in the same reference. So, I did a bit of work to discover where they originated and how they compare.

These equations were used in several NASA crop modeling studies. I have a paper containing these equations in my files (Haun, 1979). In a conversation with Stuff, he commented that these equations were used in situations where it was necessary to model crop yields at latitudes $\leq 50^{\circ}$.

The equation for latitudes $<40^{\circ}$ (Eq. [3]) is correct. The equation for latitudes $>40^{\circ}$ is not stated correctly. There is a misplaced parenthesis in the equation. It should read:

$$
\begin{gathered}
\mathrm{DL}=12.25+\left[1.6164+1.7643(\tan (\mathrm{LA})\}^{2}\right] \\
\cos (0.0172 \mathrm{CD}-1.95)
\end{gathered}
$$

The square is on the $\tan$ (LA) term, not the whole $[1.6+1.7 \tan (\mathrm{LA})]$ term.

Daylength calculated from these equations were compared with daylength calculated using a program by Barkstrom (1981). He suggests that his program calculates sunrise and sunset within $2 \mathrm{~min}$ at lat. $50^{\circ}$. The daylength calculated from the approximation for use a latitudes $<40^{\circ}$ was within $10 \mathrm{~min}$ at 
all latitudes from $0^{\circ}$ to $40^{\circ}$ throughout the year. Most of the year had daylength differences under $5 \mathrm{~min}$. This is sufficient accuracy for use in programs where hourly temperatures are estimated or where time needs to be accumulated over a period of many days.

The equation for use at latitudes $>40^{\circ}$ needs to be used with some caveats, especially at high latitudes. It works reasonably well at latitudes between $40^{\circ}$ and $50^{\circ}$. At $60^{\circ}$, however, part of the year has daylengths much shorter and part of the year has daylengths much longer than the daylength calculated using Barkstrom's program. I have not done an in-depth study using this equation, since I usually use only the equation for $<40^{\circ}$.

A comment was made on the use of degrees and radians. The daylength equations depend on latitude. Latitude is an angular measure on the Earth's surface. The equa tions contain the tangent of the latitude. Whether you get the tangent by expressing the angle in degrees or radians is immaterial. I referred to latitude by using degrees, since most people are acquainted with angular measure in degrees and latitude is routinely expressed in degrees rather than in radians.

The factor 0.0172 (Eq. [3]) in the cosine term converts climatological day to radians. You can consider day number a circular function, since it repeats every 365 (366?) days.

Scagel (2): Use of ${ }^{\circ} \mathrm{F}$ or ${ }^{\circ} \mathrm{C}$ temperature for nighttime chilling hours.

Nighttime chilling hours were determined as hours with temperatures $<45 \mathrm{~F}$ or the corresponding ${ }^{\circ} \mathrm{C}$. The hours calculated by this equation will be the same regardless of the temperature units. Note that temperature shows up in the arcsin and the exponent as a ratio, thus becoming a dimensionless quantity. If you need the hours between two temperatures such as $32 \mathrm{~F}$ and $45 \mathrm{~F}$, solve the equation(s) by setting Tc at both critical temperatures and differencing the resulting hours.

Scagel (3): Comment on order of precedence of equations.

I am not quite sure how to comment here. If you are putting together a computer program, you obviously have to calculate in the correct sequence, i.e., climatological day before daylength before chilling hours. You can calculate chill units without getting into the chill hour calculation. I usually use a "one hour" time step for calculations. One of my programs fills an array of 24 cells with temperatures, while another program solves a "DO LOOP" to calculate chill units at hourly steps using the test shown in the table. units.

Scagel (4): Comment on table for chill

This small "table" suffers from typesetting woes. Pull the right side of the table upward to get items onto the correct lines. This error was noted, but not corrected, prior to printing. Perhaps this information should have been placed in a formal table, but at the time of writing, I thought that this form worked into the flow of the paper better than referring to a separate table.

Scagel (5): Comment of Richardson reference.

Should have been Richardson et al. (1974), as shown in the Literature Cited.

Scagel (6): Comment on missing/duplicate information.

Whoops! Double the pleasure!

Scagel: Proofing the equations.

I am not sure about the final comment on proofing the equations. The equations for hourly temperature can be checked against local data, but that is not the purpose of this approach. The purpose is to develop a method to obtain meaningful values of "chill" when using minimal data sets such as daily maximum and minimum temperatures. The tabled $r$ values do a good job of showing how the total set of equations operate in South Carolina.

We have developed a South Carolina climatology of "chill" using this technique. Climatologists in other states are compiling similar climatologies. Growers are using the historical compilations along with currentseason values as input to their management decision process. Agricultural Weather Offices in North Carolina, Alabama, Tennessee, and Kentucky use the concepts described in my paper in their day-to-day operations. Regardless of the accuracy of estimating "chill", it is the precision in the yearto-year calculations that is most important.

\section{Literature Cited}

Barkstrom, B. 1981. What time does the sun rise and set? BYTE July, 9.94-114.

Haun, J.R. 1979. Wheat yield models based on daily plant-environment relationships. Proc. Crop Modeling Wkshp. Columbia, Mo, 3-5 Oct. 1977. [reprinted by USDOC/NOAA, Washington, D.C.]

Paton, W.J. and J.A. Logan. 1981. A model for diurnal variations in soil and air temperature. Agr. Met 23:205-216.

Stuff, R.G. and R.F. Dale. 1973. A simple method of calendar conversions in computer applications. Agr. Met. 12:441-442.

Sutton, O.G. 1953. Micrometerology. McGrawHill, New York. p. 180.

$$
\begin{array}{r}
\text { Dale E. Linvill } \\
\text { Agricultural Engineering Dept. } \\
\text { Clemson Univ. } \\
\text { Clemson, SC } 29634
\end{array}
$$

\section{Muscadines}

The cover story of the July 1990 issue of HortScience highlighted the history of improvement of muscadines (Vitis rotundifolia Michx.), but an error was made concern- ing hybrids of Euvitis (bunch grapes, $2 \mathrm{n}=$ $38)$ and Muscadinia $(2 n=40)$. The statement was made that hybridization of these subgenera is difficult " .... and has only been successful when Euvitis is used as the female parent". If successful means that viable progeny are produced from a cross, the authors are in error. However, this does appear to be a widely held belief and has dis couraged some from attempting this cross. One of the earliest hybridizers of muscadines and bunch grapes, Charles Dearing, reported that the female muscadine cultivars Eden, Scuppernong, and Thomas had been used successfully as females in crosses with bunch grapes (Dearing, 1917). He also reported that at least 14 different bunch grape cultivars had been used successfully as pollen sources in such crosses. In 1 year (1915), a total of 70 viable progenies were produced from such hybridization efforts. A later report (Fry, 1964) indicated similar success in obtaining hybrids from muscadine $\mathrm{x}$ bunch grape crosses.

The hybridization of Muscadinia and Euvitis is an area that has been underexploit ed. Muscadines have many useful characteristics that could be used in developing bunch grapes with a high level of disease resistance (Olmo, 1986) and stenospermocarpic muscadine cultivars could also be developed. Problems with sterility have been encountered with many aneuploid crosses in a variety of crops. This should not deter breeders from making this cross to exploit the useful characteristics of these closely related species.

\section{Literature Cited}

Dearing, C. 1917. Muscadine grape breeding. J. Hered. 8:409-424.

Fry, B.O. 1964. Fertile interspecific hybrids Vitis rotundifolia $\times$ Vitis vinifera. Georgia Agr. Expt. Sta. Mimeo. Ser. N.S. 200.

Olmo, H.P. 1986. The potential role of (vinifera $x$ rotundifolia) hybrids in grape variety im . provement. Experientia 42:921-926.

Tim Bourne Center for Viticultural Sciences Florida A\&M Univ. Tallahassee, FL 32307

\section{Author's response}

I appreciate the comments by Dr. Bourne on the recent muscadine cover article written by myself and C.P. Hegwood. Efforts over the past 130 years by Bouquet (1980), Dearing (1917), Detjen (1919), Munson (1909), Patel and Olmo (1955), Reimer and Detjen (1914), and Wylie (1871) have led to the conclusion that true hybrids obtained from crosses of Euvitis species with $V$. rotundifolia are "easily accomplished" when V.rotundifolia has been used as the male parent, but the cross succeeds "only rarely when 
rotundifolia serves as the female" (Olmo, 1986). In addition, all hybrids, regardless of whether muscadine was used as the male or female parent, have been highly sterile, producing no or very few fruit (Olmo, 1986). Thus, none of the hybrids produced have re sulted in commercially useful cultivars. However, the recent release of two hybrids as disease-resistant rootstocks for Euvitis grapes is very encouraging (Walker et al., 1989). The subject of muscadine breeding and genetics is one in need of a current, thorough review. Ron Goldy has recently submitted such a review to Plant Breeding Reviews, and I look forward to his detailed discussion of the subject, and particularly of points raised by Dr. Bourne.

\section{Literature Cited}

Bouquet, A. 1980. Vitis $\times$ Muscadinia hybridization: A new way in grape breeding for disease resistance in France. Proc. 3rd Intl. Symp. on Grape Breeding. p. 42-61.

Dearing, C. 1917. Muscadine grape breeding. J. Hered. 5:409-429.

Detjen, L.R. 1919. The limits in hybridization of Vitis rotundifolia with related species and genera.

Munson, T.V. 1909. Foundations of American grape culture. T.V. Munson \& Son, Denison, Texas.

Olmo, H.P. 1986. The potential role of (vinifera $\mathrm{X}$ rotundifolia) hybrids in grape variety im . provement. Experientia 42:921-926.

Patel, G.I. and H.P. Olmo. 1955. Cytogenetics ofVitis: I. The hybrid $V$. vinifera $\times V$.rotundi . folia. Amer. J. Bot. 42:141-159.

Reimer, F.C. and L.R. Detjen. 1914. Breeding rotundifolia grapes. North Carolina Agr. Expt. Sta. Tech. Bul. 10:1-47.

Wylie, A.P. 1871. Hybridization of rotundifolia grapes. Amer. Pomol. Soc. Proc. 13:113-116.

William C. Olien Dept. of Horticulture Clemson Univ Clemson, SC 29634-0375

\section{Corrigenda}

- In the article, "Liberty Hyde BaileyFather of American Horticulture", by John G. Seeley [HortScience 25(10):1204-1210, Oct. 1990], the author wishes to note an error in the dates of Bailey's presidency of the Society for Horticultural Science. The correct dates are 1903-1907.

- Photographic credit for the front cover of HortScience 25(10):1197 Oct. 1990 was incorrect. The cover photograph was taken by John Lynch of Lexington, Ky.
- The following paper was not printed in the Program \& Abstracts [HortScience 25(9), Sept. 1990]:

700 GROWTH OF CONTAINERIZED TRANSPLANTS SUPPLEMENTED WITH VARYING N AND P RATIOS Zvi Karchi* and Daniel J. Cantliffe, Vegetable Crops Dept., Univ. of Florida, Gainesville, FL 32611

Lettuce cultivars Empire and Floracal 50011 were grown in Todd 125 planter flats in a greenhouse to study the interaction of $\mathrm{N}$ and $\mathrm{P}$ on early stages of transplant growth. Nutrient solutions consisting of $300 \mathrm{ppm} \mathrm{N}$ and $\mathrm{P}$ in varying ratios which included $50: 50 ; 17: 83 ; 10: 90$ and $83: 17 \mathrm{~N}: \mathrm{P}$ on a percentage basis, were compared to a water treatment. Plants were sampled 4 times during a period of 22 days starting 14 days after seeding. The water treatment resulted in the lowest fresh weights of leaves, roots and the total plant. On the other hand, the water treatment consistently promoted greater root dry matter on a percent total weight basis in all sampling dates. The $50 \mathrm{~N}: 50 \mathrm{P}$ treatment promoted greater fresh weights of leaves and plants compared to the water treatment, but led to lower fresh and dry weights of roots on a percentage basis. On the final sampling date, the high P treatments promoted significantly greater fresh weights of leaves, roots, and plants and dry weight of leaves and plants, but lower dry weight of roots, compared to the water treatment. High $\mathrm{P}$ mediated the depressing effect of $\mathrm{N}$ on root growth and hastened balanced growth of the transplants.

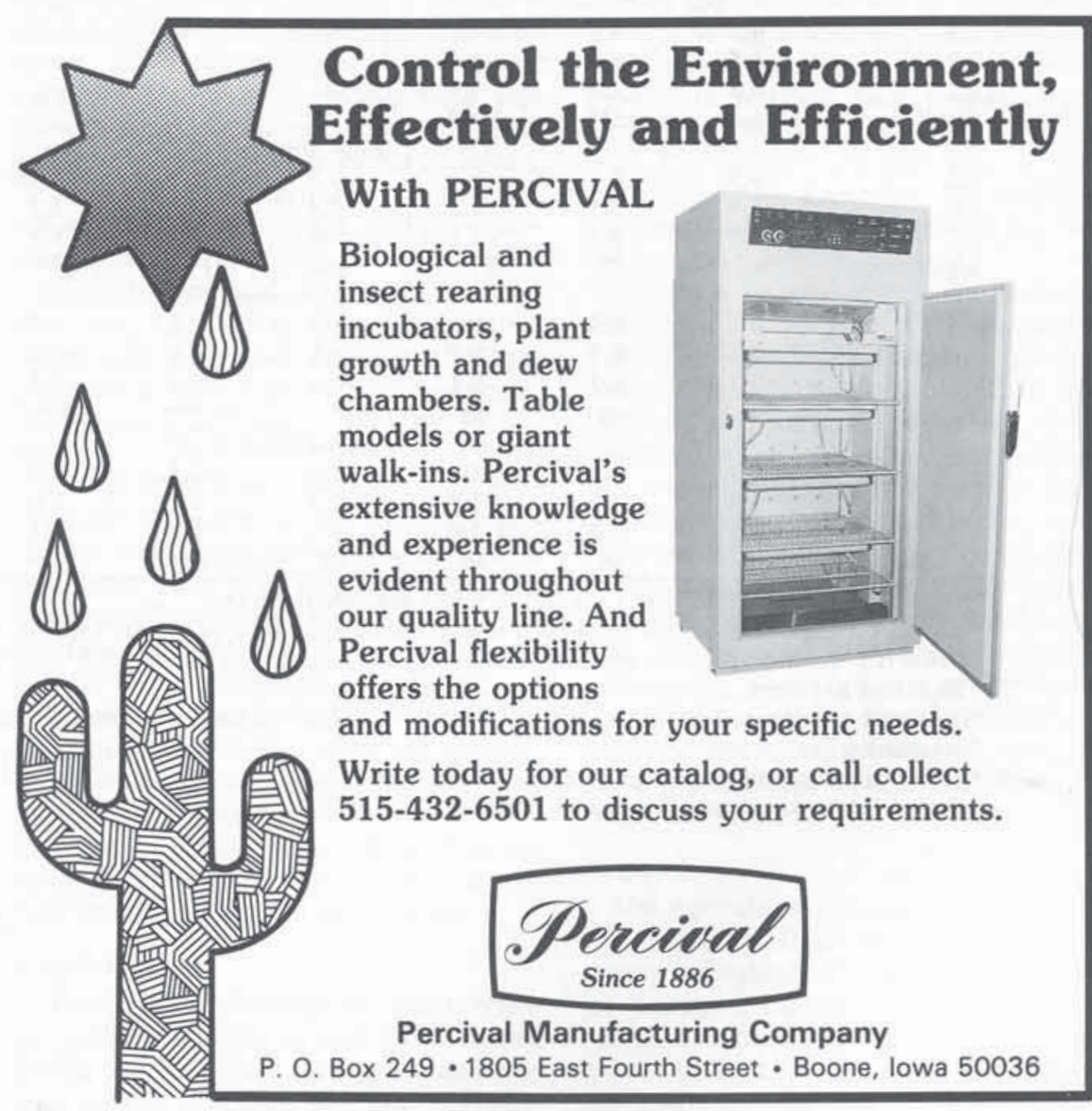

